\title{
Familial hypoplasia of the iris stroma associated with glaucoma
}

\author{
J. R. WEATHERILL AND C. T. HART \\ United Sheffield Hospitals
}

Familial hypoplasia of the iris stroma associated with glaucoma has been recorded on four occasions, this being the first report in the English literature. In all cases the condition has been inherited as an autosomal dominant trait.

Berg (1932) described thirteen men and nine women affected in six generations. They were first seen between the ages of 16 and 43 years, and eight eventually became blind in both eyes. The irides of the affected patients were described as thin, with absence of normal surface markings. The colour varied from "dark brown", "muddy brown", and "dark grey-brown" to "deep grey" and "grey blue". Only one patient had a possibly normal iris colour, described simply as "brown". The pigment epithelium was intact in all patients except one who had a small circular defect about I $\mathrm{mm}$. diameter; this was associated with ectasia of the superior limbus. The pupil was central and active in all of them. Two had "hydrophthalmia" but they were first seen at the ages of 17 and 2 I years respectively.

Hambresin and Schepens (1946) reported ten men and nine women affected in six generations. All became blind by the age of 40 years and one child was already blind at the age of 9. The irides of the affected patients were always a dark chocolate brown, with easily visible iris vessels and no normal surface markings. The members of this family were aware of the significance of this appearance and they always scrutinized the eyes of each infant at birth. "Si ce sont des yeux couleur chocolat, disent-ils, c'est encore la mauvaise vue de la famille". The pupils were central and active. In spite of the severity of the glaucoma none of these patients had buphthalmos although one did have a myopia of - I4 D. Hambresin and Schepens also found that their affected patients had a "choroiditis"; in some it was diffuse, in others confined to the posterior pole. In the peripheral fundus there were small yellow spots with darker centres reminiscent of syphilis.

François, Deweer, and van den Berghe (1950) described six women and four men in six generations who had glaucoma and normal open angles. Six of these patients have become blind-two in the fifth decade. The irides of the affected patients were described as "greyish" and this was considered to be a bad prognostic sign by members of the family. Unfortunately, no further details of the appearance of the iris are given and one cannot be certain that they had hypoplasia of the iris stroma, although Waardenburg, Franceschetti, and Klein ( $196 \mathrm{I}$ ) included them under this heading.

McCulloch and MacRae (1950) described fourteen women and four men in five generations with glaucoma and abnormal irides. Ten were examined by the authors and nine 
of these were found to have slatey-grey, thin, "slightly atrophic" irides. The pupils were central and active. None of the seventeen normal members of the family had unusual $\frac{0}{3}$ irides. The angles were recorded as normal in two patients. One member of the family had buphthalmos but he was not examined. MeCulloch and MacRae postulated that the $\overrightarrow{\vec{F}}$ genes for eye colour are linked to the genes determining glaucoma, but as iris colour is $\overrightarrow{0}$ normally determined by the intensity of the pigmentation and not by the structure of the stroma, it would seem more likely that their patients' abnormal iris colour was due to stromal hypoplasia. Furthermore, Waardenburg and others (I96I) supported this view $\triangle$ on the grounds that iris colour is determined by recessive genes which would be latent in का heterozygotes.

\section{Methods of investigation}

Several members of the family described here (Fig. I) attended different eye clinics for $\mathcal{E}$ treatment of glaucoma. When the familial nature of the disease was recognized the whole family was asked to attend for examination. There are 77 members, of whom six have $\underset{\omega}{\vec{\omega}}$ died and one has emigrated. Although we have no hospital records of these people, their $ᄋ$ descendants have been able to give us useful information. Three further members of the family are completely blind with advanced glaucoma and were unwilling to attend for further examination.

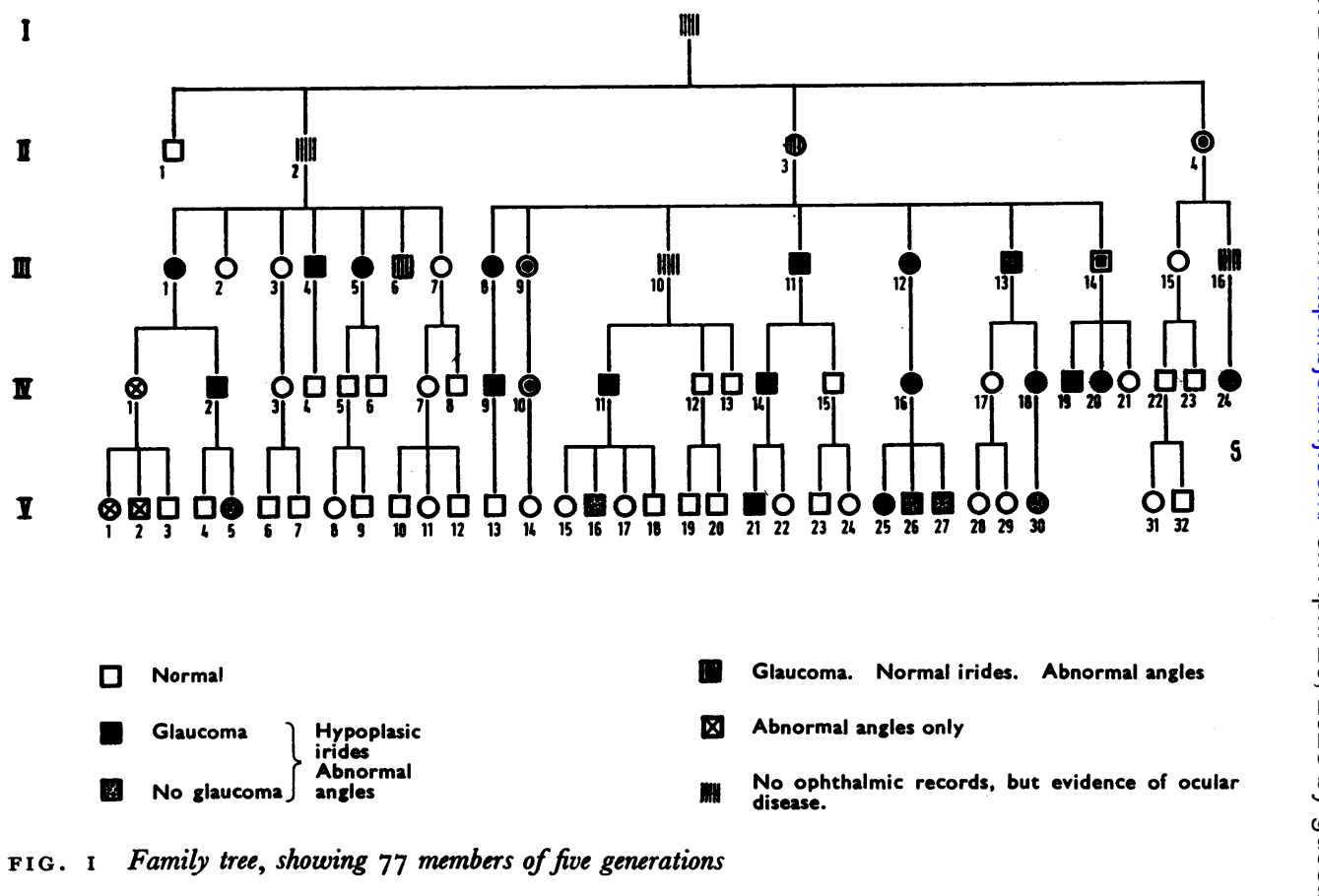

All intraocular pressures were measured with a Goldmann applanation tonometer and $\frac{0}{\vec{D}}$ the visual fields were estimated with a $3 \mathrm{~mm}$. white target on a Bjerrum screen at 2 metres. $\frac{?}{\mathbb{Q}}$

The diagnosis of glaucoma was made on the association of intraocular pressure greater than $21 \mathrm{~mm}$. $\mathrm{Hg}$, cupped discs, and contracted visual fields when these could be measured. 
Four patients have normal discs and full fields but are considered to have glaucoma on the following grounds.

IV II intraocular pressures of $45 \mathrm{~mm}$. $\mathrm{Hg}$ in the right eye and $42 \mathrm{~mm} . \mathrm{Hg}$ in the left at his first attendance; the glaucoma is controlled on pilocarpine and epinephrine.

IV 18, aged 20 years at her first attendance, had an intraocular pressure of $25 \mathrm{~mm} . \mathrm{Hg}$ in each eye associated with a facility of aqueous outflow $(\mathrm{C})$ of only 0.13 in each eye; $\mathrm{Po} / \mathrm{C}=192$.

IV 19 had an intraocular pressure of $30 \mathrm{~mm}$. $\mathrm{Hg}$ each eye at his first attendance.

IV 20 is only 16 years old but had an intraocular pressure of $21 \mathrm{~mm}$. $\mathrm{Hg}$ in the right eye and $23 \mathrm{~mm}$. $\mathrm{Hg}$ in the left with an outflow facility of $\mathrm{o} \cdot 10$; in each eye; $\mathrm{Po} / \mathrm{C}=2 \mathrm{IO}, 230$ (right and left).

\section{Clinical observations}

IRIS

In all patients the appearance of both irides is identical. With one exception (IV 24) the irides are either clearly normal or grossly abnormal. The basic defect is extreme attenuation of the iris stroma, so that the pigment layer and sphincter pupillae are clearly visible through the few remaining coarse strands. At the root of the iris the scalloped border of the posterior edge of the pigment layer is seen clearly. There are no defects in the pigment epithelium, and the pupil is circular and active. When seen without magnification in moderate illumination the "brown" irides appear to be the colour of dark bitter chocolate (see III 13, Figs 2 and 3, col. pl., overleaf).

"Blue" irides appear as a very dark slate grey (see IV 16, Figs 4 and 5; and V 25, Figs 6 and 7).

These iris colours never occur normally and the patients are frequently aware of the abnormality.

\section{ANGLES}

In all cases the angle appearances are similar in each eye. Two types are found in the affected members of this family (see Fig. I).

Type $A$ These are grossly abnormal. The whole angle is filled with yellow tissue covered with fine blood vessels. No normal angle structures apart from Schwalbe's line can be seen. All patients with Type A angles have hypoplastic irides.

Type $B$ The iris is inserted anteriorly into the region of the trabecular meshwork. Many fine iris processes span the angle from the iris root to Schwalbe's line. None extends onto the cornea. There are a few abnormal vessels coursing among the iris processes.

\section{OTHER OCULAR ABNORMALITIES}

One patient, III I 3 (Figs 2 and 3), has poorly differentiated corneo-scleral junctions but no glaucoma. None of our patients had choroiditis or buphthalmos. Our findings agree with those of previous reports in that a low degree of myopia is common in this condition. There are no hypermetropes in this family. 
I N HE R I T A N C E

The family consists of 77 members, of whom thirty are known to have abnormalities of the anterior segment; 24 of these have so far developed glaucoma. None has glaucoma without abnormality of the angle and thus we may assume that the glaucoma is related to these anomalies. The mode of inheritance of the anterior segment defects is an autosomal dominant trait. The evidence for this using the criteria of Pearce (1968) is:

(I) Affected individuals were always found to have an affected parent.

(2) Personal observations have shown transmission through three generations in eight siblings.

(3) The affected number of males (14) compared with that of affected females (16) is not significantly different.

(4) The number of affected individuals - thirty at least and probably 35-compared with the number unaffected $\left(4^{2}\right)$ is not significantly different.

RELATIONSHIP OF GLAUCOMA TO ANTERIOR SEGMENT ANOMALIES

Of the twenty patients in this family who have glaucoma, seventeen have attended for gonioscopy and all of these have abnormal angles-eight Type A and nine Type B. Only one adult patient with Type A angles (IV 24) does not have glaucoma, but her facility of outflow is very good $(\mathrm{C}=0.36$ right and left $)$ and the intraocular pressure within normal limits, so that one must conclude that three is no direct correlation between angle appearances and glaucoma. Two very young children ( $\mathrm{V}_{2} 6$ and $\mathrm{V}_{27}$ ) have hypoplasic irides, Type A angles, and normal intraocular pressures when measured under an anaesthetic. Furthermore, there are three patients with Type B angles and no evidence of glaucoma (IV I, $\mathrm{V}_{\mathrm{I}}, \mathrm{V}_{2}$ ). One of these (IV I) reached the age of 37 years with entirely normal outflow.

Of the seventeen patients with glaucoma and known angle anomalies, thirteen have iris hypoplasia, but four have normal irides (II 4, III 9, I4, IV I0). However, two of the children of III 14 have hypoplasic irides and glaucoma.

Conversely only two adults have iris hypoplasia and no glaucoma (III I3, IV 24).

Five children aged $6,4,4,2$, and 2 months $\left(\mathrm{V}_{5}, 16,26,27,3^{0}\right)$ have hypoplasic irides and normal intraocular pressures, but they may well develop glaucoma. Clearly, in this family, there is a strong association between iris anomalies and glaucoma, but there is not a complete linkage.

\section{Discussion}

The crucial importance of gonioscopy in the classification of glaucoma was not widely appreciated until very recently and for this reason it is impossible to decide how many of the reports in the literature of "chronic glaucoma" inherited as a dominant trait are pedigrees of true chronic simple glaucoma. It is our impression that chronic simple glaucoma is rarely, if ever, inherited as a dominant trait and almost all cases of dominantly inherited glaucoma are due to visible anterior segment anomalies. The corollary of this is that the relatives of patients with glaucoma secondary to anterior segment defects should be examined by an ophthalmologist. The present investigation revealed four adults and 

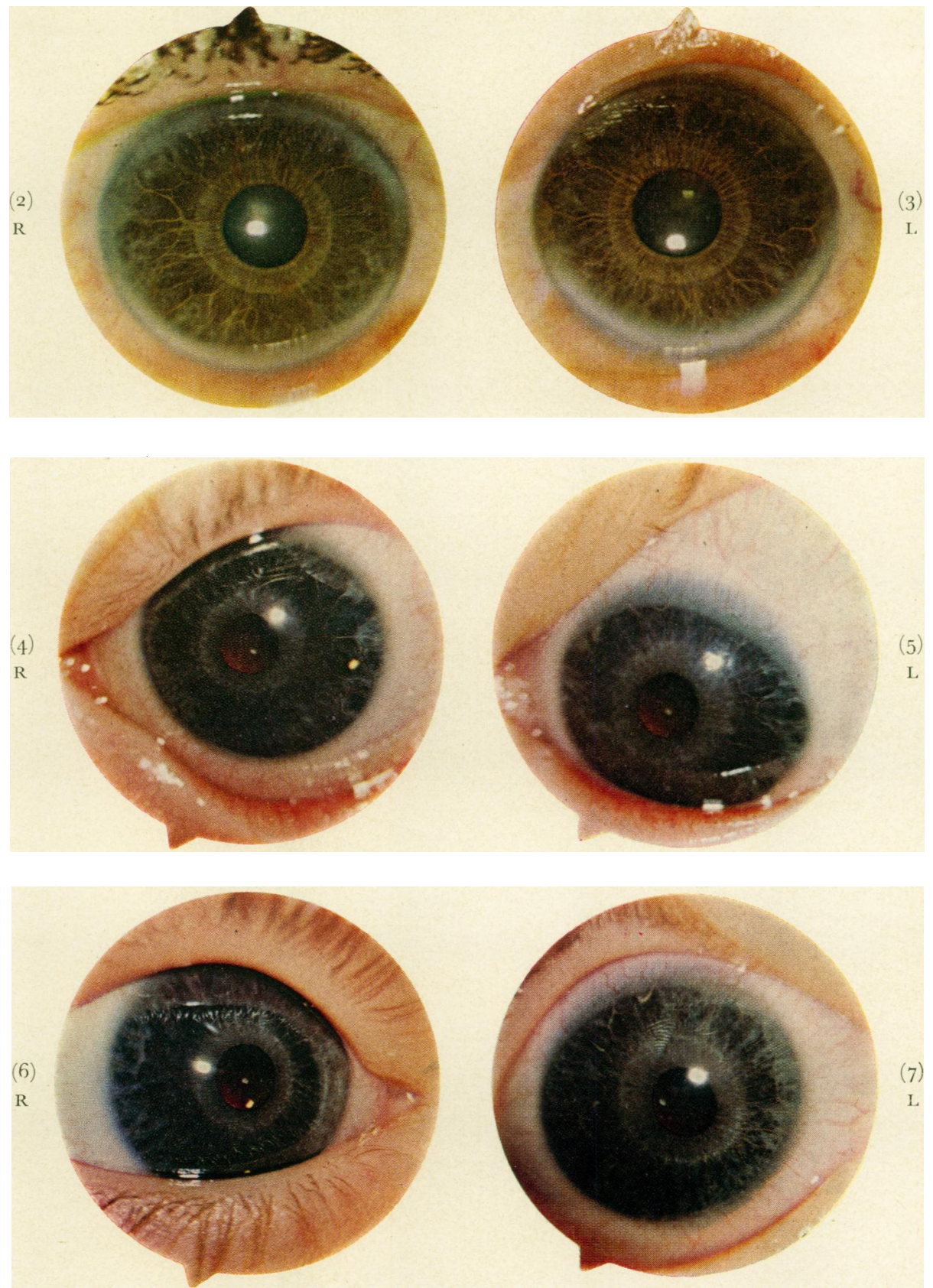

FIGS 2 and 3 Patient III I3. The pigment layer is clearly visible between remaining strands of brown stroma. Sphincter pupillae normal

FIGS 4 and 5 Patient IV 16 . Irides similar to Figs I and 2, except that the remaining stroma is blue and the impression is that of a dark slate-blue iris

FIGS 6 and 7 Patient $\mathrm{V} 25$ (daughter of $I V{ }_{1} 6$ ). Irides closely resemble those of the mother. 
three children with unsuspected glaucoma, and a further five children who must be regarded as "glaucoma suspects".

In diseases due to autosomal dominant genes there is usually a $5^{\circ}$ per cent. risk that the child of an affected parent will inherit the condition. In some disorders, for example, retinoblastoma, the gene is not fully penetrant and the risk may be less. In this particular family the gene appears to be fully penetrant but has variable expression, which may lull a prospective parent into a false sense of security. III I 4 has normal irides and was unaware of any ocular abnormality other than a low degree of myopia; he has, however, transmitted the disease to two of his three children. III I 3 has no glaucoma, but his daughter IV 18 almost certainly has early glaucoma.

It is frequently suggested (for example, by Hambresin and Schepens, I946) that pedigrees of families suffering from insidious disorders show anticipation. There is no evidence of anticipation of the glaucoma in this family although the average age at the first attendance in each successive generation is lower (II-69; III-52; IV-30; V-5). The most important reason for the apparent anticipation is that the members of the more recent generations were actively sought for the purpose of this investigation, but the older members of the family did not seek medical advice until the disease was far advanced. Even if the younger patients had not been asked to attend for examination they would probably have sought medical advice sooner than their forebears as there is nowadays less fear of hospitals. Further evidence against anticipation in this family is the absence of buphthalmos, and the absence of complete blindness in any members of the IVth or Vth generation.

The mechanism of the glaucoma in our patients is presumably a progressive obstruction of the drainage channels deep in the trabecular meshwork. The appearances seen on gonioscopy are not directly related to the glaucoma because, whereas all the patients with glaucoma have abnormal angles, not all patients with abnormal angles have glaucoma. Further evidence of the indirect relationship between the angle appearances and glaucoma is the absence of buphthalmos. In true infantile glaucoma, where the angle defect is directly responsible for the raised pressure, the glaucoma is manifest within the first few months of life and the globe enlarges. There is still controversy on the precise pathogenesis of infantile glaucoma but most are now agreed that resorption of mesoderm plays no part in the formation of a normal angle or the abnormal angle which causes infantile glaucoma (Worst, 1968). The appearance of the angles of our patients is different from that seen in infantile glaucoma, in which the only essential feature is an anterior insertion of the iris. The trabecular tissues frequently appear slightly opalescent and thicker than normal, and some observers have seen an almost transparent membrane which lines the inner surface of the angle. It is thought that the obstruction to outflow in infantile glaucoma lies close to the inner aspect of the angle, which accounts for the success of goniotomy. Two goniotomies failed to lower the intraocular pressure in one member of this family ( $\mathrm{V}_{25}$ : Figs 6 and 7). Type A angles have not been studied histologically, but they clearly contain excess tissue and are not, therefore, the result of delayed or arrested development. Type B angles have been described in great histological detail by Allen, Burian, and Braley (1955), who suggest that this type of angle is not due to arrest of normal development, but to "excessive laying down of mesodermal tissue in embryonic and foetal eyes ... which in man may represent a genetically determined atavistic trait".

The iris changes are almost certainly congenital and static. None of our patients has any of the appearances of essential iris atrophy or iridoschisis, and in none is there any defect of the sphincter pupillae or pigment epithelium such as is found in Rieger's anomaly. 


\section{Summary}

A family in which hypoplasia of the iris stroma associated with glaucoma has been trans-⿳亠丷厂 mitted as an autosomal dominant trait over five generations is presented. The importance of examining relatives of patients who suffer from inherited disorders is stressed. A plea is $\stackrel{\vec{N}}{\rightarrow}$ made for the inclusion of gonioscopic findings in reports of familial glaucoma.

We should like to thank Mr. A. Stanworth, Miss M. A. C. Jones, and Mr. I. Strachan for permission to publish details of their patients. Mr. Stanworth also gave helpful advice on the preparation of this paper.

\section{References}

allen, L., Burian, H. M., and braley, A. E. (1955) A.M.A. Arch. Ophthal., 53, 799 BERG, F. (1932) Acta ophthal. (Kbh.), ro, 568

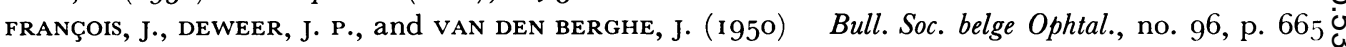
hambresin, L., and SChepens, c. (1946) Bull. Soc. franf. Ophtal., 59, 2 I 9 mcGulloch, C., and maCRAe, D. (1950) Trans. Canad. ophthal. Soc., p. 79 PEARCE, w. G. (i968) Brit. F. Ophthal., 52, 73 WAARDENburG, P. J., FRANCESchetti, A., and Klein, D. (I96I) "Genetics and Ophthalmology", vol. I, p. 69o. Blackwell, Oxford WORST, J. G. F. (1968) Invest. Ophthal., 7, 127 